\title{
Retrospective observational cohort study on cosmetic outcome of using Ti-Ni memory alloy wire for intradermal suture following mastectomy in patients with breast cancer
}

\author{
GANG LI $^{1}$, SIDA QIN ${ }^{1}$, XIN SUN $^{1}$, JIANSHENG WANG ${ }^{1}$, YUNFENG ZHANG $^{1}$, \\ JIA ZHANG ${ }^{1}$, JING ZHANG ${ }^{1}$, SHOU-CHING TANG ${ }^{2,3}$ and HONG REN ${ }^{1}$
}

\begin{abstract}
${ }^{1}$ Department of Thoracic Surgery and Oncology, Cancer Center, The First Affiliated Hospital of Xi'an Jiaotong University, Xian, Shaanxi 710061, P.R. China; ${ }^{2}$ Division of Hematology and Oncology, The Georgia Cancer Center, Augusta University, Augusta, GA 30912, USA; ${ }^{3}$ Tianjin Medical University Cancer Institute and Hospital, Tianjin 300070, P.R. China
\end{abstract}

Received April 2, 2017; Accepted October 3, 2017

DOI: $10.3892 / 01.2017 .7603$

\begin{abstract}
The method of suturing for incisions is crucial for the comprehensive treatment of clinical patients with breast cancer. Suturing is considered a major part of post-surgical recovery and may serve as a marker for evaluation of surgical outcome. The present study aimed to establish an effective means of suturing for patients who received modified radical surgery that helps to improve the cosmetic outcome of the incision. Enrolled patients were divided into an active and a control group. Ti-Ni memory alloy wire for intradermal suture in the active group and silk for interruption suture in the control group were applied to assess the different prognosis-associated factors. The Vancouver Scar Scale (VSS) was used to evaluate the wound size and the recovery time of the scars. The association between diabetes and the number of days of wound healing was also analyzed. The results indicated that the mean VSS score of the active group was decreased compared with that of the control group $(\mathrm{P}<0.001)$. The VSS scores of four main features (vascularity, pigmentation, pliability and height) between the two groups also statistically differed $(\mathrm{P}<0.001)$. Furthermore, the mean number of days of wound healing was significantly decreased for the active group compared with that for the control group ( $\mathrm{P}=0.0026)$ in the patients with diabetes. In addition, the usage of Ti-Ni
\end{abstract}

Correspondence to: Dr Hong Ren, Department of Thoracic Surgery and Oncology, Cancer Center, The First Affiliated Hospital of Xi'an Jiaotong University, 277 Yanta West Road, Xian, Shaanxi 710061, P.R. China

E-mail: dooopenit@163.com

Dr Shou-Ching Tang, Division of Hematology and Oncology, The Georgia Cancer Center, Augusta University, 1411 Laney Walker Blvd, Augusta, GA 30912, USA

E-mail: stang@augusta.edu

Key words: mastectomy, Ti-Ni memory alloy wire, scar, cosmetic, intradermal suture memory alloy wire was able to decrease the mean number of wound healing days between patients with diabetes and their non-diabetic counterparts $(\mathrm{P}=0.7009)$. The present study indicated that intradermal suture offers improved cosmetic outcome for patients undergoing mastectomy with or without axillary surgery. This technique may be useful for preventing scar overgrowth and for facilitating the recovery process in patients with diabetes.

\section{Introduction}

In 1882, Halsted pioneered the radical resection of the breast. Breast surgery methods have changed since and clinicians commonly perform breast-conserving surgery. However, the optimal approach for radical resection remains controversial (1). Along with social progress and improvements in the quality of life, patients with cancer, particularly patients with breast cancer have increasing requirements for the function and cosmetic outcome following surgery $(2,3)$. A previous study identified that $61 \%$ of patients reported that the opinions of their partners of the scars were important to them (4). The way an incision is closed and managed post-operatively affects cosmetic outcome (5). Historically, in breast cancer surgery, simultaneously ensuring treatment effect, shrinking excision scope and attending to the cosmetic effect has been important (6). To improve the aesthetic results for female patients undergoing breast cancer surgery, surgical techniques have been developed to render scars less noticeable $(7,8)$.

In China, the majority of patients with breast cancer are treated with modified radical surgery using discontinuous silk suture, which leaves a very noticeable scar (9). A study on cosmetic surgery identified that $50 \%$ of patients reported that the extent of the visual scar greatly affected their self-assessment of the outcome (10).

Previous studies have assessed how drugs can be used to decrease scarring but the results demonstrated that there remains no 'gold standard' for the prevention and treatment of hypertrophic scars $(11,12)$. The authors of the present study evaluated the methods of closing wounds in modified radical surgery in April 2014 and proposed using intradermal 
suture with Ti-Ni memory alloy wire (13). After $>2$ years of practice and observation, the wounds of patients with scarring markedly improved following intradermal suture with Ti-Ni memory alloy wire.

The primary objective of the present study is to assess the impact of using a Ti-Ni memory alloy wire intradermal sutures on the cosmetic outcome of the wound scar within 25 weeks following mastectomy.

\section{Materials and methods}

Study design. Prior to the start of the present study, the methods of surgical suturing were altered and the postoperative effects were observed. After $>2$ years of observing and evaluating Vancouver Scar Scale (VSS) scores and the number of wound healing day(s), the present study reviewed the retrospective data. The present study is a retrospective observational cohort study with parallel groups and compares conventional closure with closure using intradermal sutures and Ti-Ni memory alloy wire in patients undergoing mastectomy with or without axillary surgery.

Setting. The present study included diagnostic surgery and post-operative adjuvant chemotherapy for patients with breast cancer in the Department of Thoracic Surgery and Oncology of the First Affiliated Hospital of Xi'an Jiaotong University (Shaanxi, China), a process that took $\sim 6$ months. The patients were treated with interrupted suture or intradermal suture.

Inclusion and exclusion criteria. The inclusion criteria were as follows: i) Female patients with operable breast cancer (invasive carcinoma and/or ductal carcinoma in situ); ii) age, $\geq 18$ and $\leq 85$ years; iii) scheduled for mastectomy either alone or in association with axillary clearance; iv) either sentinel lymph node biopsy or standard level I/II axillary node dissection (14); v) written hospital-approved informed consent by the patient; and vi) surgical wound classified class I (Surgical Wound Classification) (15). Patients were excluded if any of the following criteria were met: i) Undergoing surgery for modified radical mastectomy with immediate breast reconstruction, cosmetic breast operations, reduction, expansion, insertion of a prosthesis, duct ectasia, infective breast disease or implant; ii) surgical wounds identified as class II, III or IV using Centers for Disease Control surgical site infection Surgical Wound Classification (15); iii) inflammatory breast cancer or skin ulceration; iv) presence of physical or psychiatric conditions that could impair outcome assessment and intended follow-up (5); v) personal or family skin scar history; vi) received an experimental drug or used an experimental medical device within 30 days prior to the planned start of treatment; vii) employees of the assessor associated with the proposed study or other studies under the direction of that assessor; and viii) unlikely to comply with chemotherapy or complete the 25-week follow-up visit.

Patients. The first patient received intradermal sutures using Ti-Ni memory alloy wire in April 2014. In total, 98 female patients aged between 24 and 74 years, categorized into the active $(n=50)$ and control $(n=48)$ groups, were enrolled between April 2014 and April 2016. A total of 10 patients suffered from diabetes in the active group and 9 patients suffered from diabetes in the control group. The patients of control group were treated with traditional methods of wound closure. The present study reviewed all patient data for those admitted to the Second Department of Thoracic Surgery of the First Affiliated Hospital of Xi'an Jiaotong University (Shaanxi, China) who met the inclusion criteria. The present study focused on scarring. Baseline data were collected following enrollment during the therapy period. The First Affiliated Hospital of Xi'an Jiaotong University Ethics Committee approved the present study. Written informed consent was obtained from all patients.

Study interventions. Experienced breast surgeons using a standardized technique performed mastectomies (16). The skin incision included the tumor biopsy site, any invaded or edematous skin and the nipple-areola complex (17). The present study addressed the type of wound closure in mastectomy. The patients were divided into two groups, and the two groups were distinguished by the use of two different types of wound closure. In the intradermal suture group, intradermal suture using Ti-Ni memory alloy wire was implemented. In the conventional closure group, the incision was closed using the interrupted transcutaneous pattern with Chinese silk (Fig. 1). These two sutures were removed when the wounds were adequately healed (i.e., re-establishment of normal tissue integrity).

All patients were provided with a drainage tube and suction bottle to prevent subcutaneous seroma following mastectomy. All patients received chemotherapy and the same follow-up plan, including chest-abdominal computed tomography and tumor markers, was implemented every 3 months $(18,19)$. The scars were assessed 25 weeks following mastectomy. All scars were assessed independently by three observers (one oncologist and two breast cancer research associates) on the same day, using the VSS. The VSS observes four physical characteristics of scars: Vascularity, pigmentation, pliability and height $(20,21)$. Each variable contains ranked subscales that may be summed to obtain a total score ranging from 0 to 13 , with 0 representing normal skin (Table I) $(20,21)$.

Statistical analysis. All statistical analyses were performed using computer software SPSS (version 16.0; SPSS, Inc., Chicago, IL, USA). In the present study, the differences between the baseline characteristics of patients were compared using Fisher's exact test for the different categories and independent sample t-test for continuous variables. The endpoint means of the VSS scores were analyzed using independent sample t-test. $\mathrm{P}<0.05$ was considered to indicate a statistically significant difference.

\section{Results}

Characteristics of enrolled patients. All patients completed the present study. The baseline characteristics of the patients were provided (Table II). The present study compared the baseline characteristics of the two groups. The groups were similar in terms of mean age $(P>0.05)$, body mass index $(\mathrm{P}>0.05)$, operating time $(\mathrm{P}>0.05)$, blood loss $(\mathrm{P}>0.05)$, length 
Table I. Vancouver Scar Scale for assessment of the physical characteristics of scars.

\begin{tabular}{|c|c|}
\hline Characteristic & Score \\
\hline \multicolumn{2}{|l|}{ Vascularity } \\
\hline Normal & 0 \\
\hline Pink & 1 \\
\hline Red & 2 \\
\hline Purple & 3 \\
\hline \multicolumn{2}{|l|}{ Pigmentation } \\
\hline Normal & 0 \\
\hline Hypopigmentation & 1 \\
\hline Hyperpigmentation & 2 \\
\hline \multicolumn{2}{|l|}{ Pliability } \\
\hline Normal & 0 \\
\hline Supple (flexible with minimal resistance) & 1 \\
\hline Yielding (gives way to pressure) & 2 \\
\hline $\begin{array}{l}\text { Firm (inflexible not easily moved; } \\
\text { resistant to manual pressure) }\end{array}$ & 3 \\
\hline $\begin{array}{l}\text { Ropes (rope-like tissue that blanches } \\
\text { with extension of scar) }\end{array}$ & 4 \\
\hline $\begin{array}{l}\text { Contracture (permanent shortening of scar } \\
\text { leading to deformity or distortion) }\end{array}$ & 5 \\
\hline \multicolumn{2}{|l|}{ Height, $\mathrm{mm}$} \\
\hline Normal (flat) & 0 \\
\hline$<2$ & 1 \\
\hline $2-5$ & 2 \\
\hline$>5$ & 3 \\
\hline Total score & 13 \\
\hline
\end{tabular}

of post-operative hospital stay $(\mathrm{P}>0.05)$, pathological stage (7th edition; American Joint Committee on Cancer/Union for International Cancer Control tumor-node-metastasis staging systems; $\mathrm{P}>0.05)$ and medical history $(\mathrm{P}>0.05)(22)$.

Cosmetic outcome. Results demonstrated that the mean VSS score of the active group was decreased (indicating improved cosmetic outcome) compared with that of the control group $(\mathrm{P}<0.001$; Table III). The four features of the VSS scores differed statistically $(\mathrm{P}<0.001)$. The cosmetic results of suturing for four cases are also presented in Fig. 2. A comparison of cosmetic results between the experimental and control groups is shown in Fig. 3, and statistical differences between the active and control groups are shown.

Unexpected benefits of using memory alloy wire in patients with diabetes. Aside from improved recovery from the surgical wound, the present study also observed accelerated wound healing in both groups. The mean number of wound healing days required to take out stitches was decreased for the active group compared with that for the control group in patients with diabetes ( $\mathrm{P}=0.0026$; Fig. 4). Results indicated that using Ti-Ni memory alloy wire was able to decrease the days of wound healing required between patients with diabetes and their non-diabetic counterparts ( $\mathrm{P}=0.7009$; Fig. 4). Results
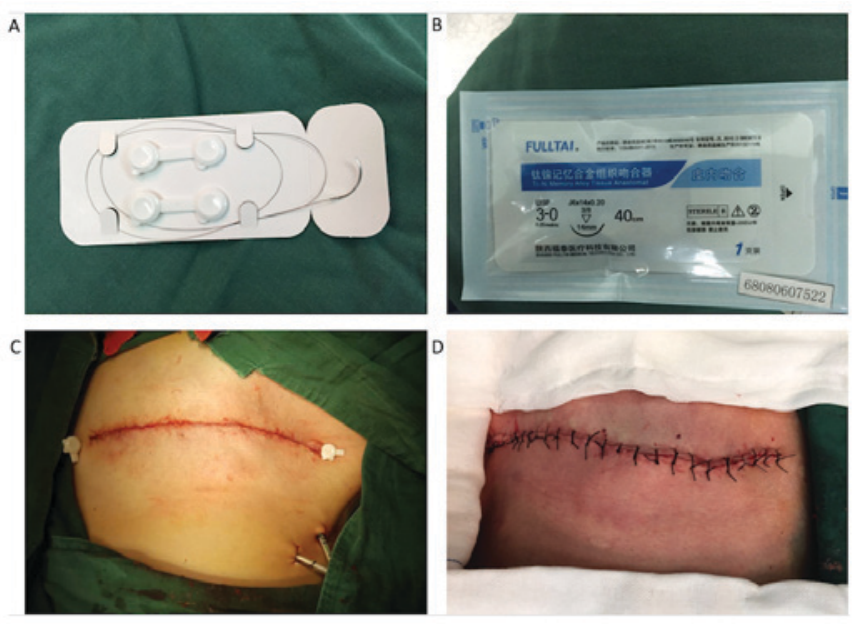

Figure 1. Suture material and types of suture. (A) The Ti-Ni memory alloy wire. (B) The outer packaging of the Ti-Ni memory alloy wire. (C) An incision corresponding with intradermal suture with the Ti-Ni memory alloy wire. (D) An incision corresponding with closure with interrupted transcutaneous pattern with Chinese silk.
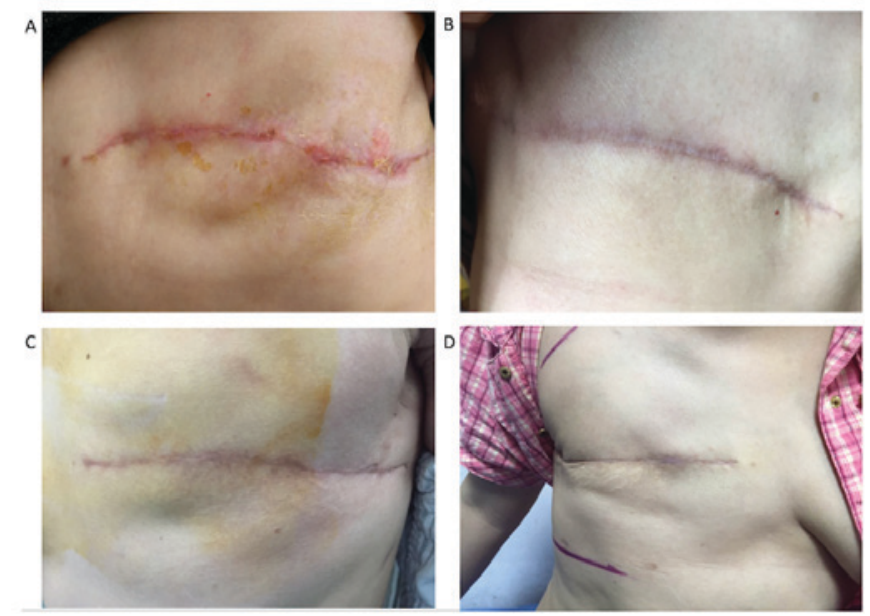

Figure 2. Cosmetic results following intradermal suturing for four cases. (A) Patient with a pink, flat, soft scar. (B) Patient with a purple, flat, soft scar. (C) Patient with a brown, flat, supple scar. (D) Patient with a brown, raised (>2 mm), supple scar.

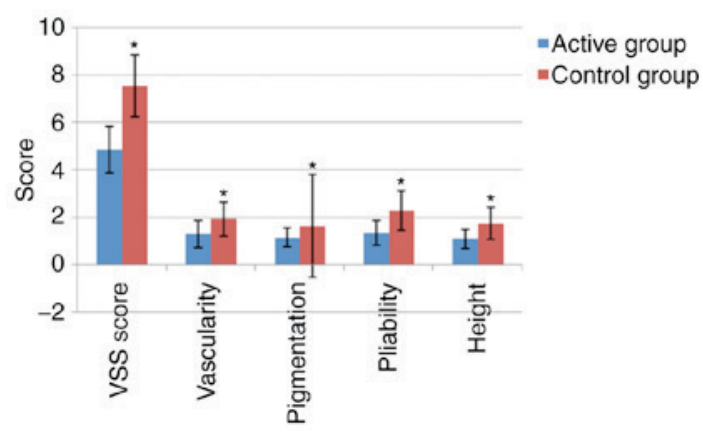

Figure 3. Comparison of cosmetic results between the experimental and control groups as displayed by a column chart. ${ }^{*} \mathrm{P}<0.001$ vs. active group. VSS, Vancouver Scar Scale.

of the present study suggested that using memory alloy facilitated wound healing. 
Table II. Comparison of the baseline characteristics of patients who underwent mastectomy ( $\mathrm{n}=98)$.

\begin{tabular}{|c|c|c|c|c|}
\hline Characteristics & Active group $(n=50)$ & Control group $(n=48)$ & $\chi^{2}$ or t-value & P-value \\
\hline Mean \pm SD age, years & $47.38 \pm 11.64$ & $46.58 \pm 11.79$ & 0.337 (t-value) & 0.737 \\
\hline BMI, $\mathrm{kg} / \mathrm{m}^{2}$ & $26.55 \pm 4.38$ & $27.17 \pm 4.21$ & 0.710 (t-value) & 0.479 \\
\hline Diabetes, n (\%) & 0 & $1(2.08)$ & & 0.490 \\
\hline Pulmonary history (COPD), n (\%) & $1(2.00)$ & 0 & & 1.000 \\
\hline Cardiac history (coronary disease), n (\%) & 0 & $1(2.08)$ & & 0.490 \\
\hline Smoking history, $\mathrm{n}(\%)$ & $2(4.00)$ & $2(4.17)$ & & 0.676 \\
\hline Working outside the home, n (\%) & $6(12.00)$ & $4(8.33)$ & & 0.741 \\
\hline Pathological stage, n (\%) & & & $1.344\left(\chi^{2}\right.$-value $)$ & 0.969 \\
\hline I & $1(2.00)$ & $1(2.08)$ & & \\
\hline IIA & $12(24.00)$ & $12(25.00)$ & & \\
\hline IIB & $15(30.00)$ & $17(35.42)$ & & \\
\hline IIIA & $9(18.00)$ & $8(16.67)$ & & \\
\hline IIIB & $11(22.00)$ & $9(18.75)$ & & \\
\hline IIIC & $1(2.00)$ & $1(2.08)$ & & \\
\hline IV & $1(2.00)$ & 0 & & \\
\hline Mean \pm SD operating time, min & $100.98 \pm 11.31$ & $103.54 \pm 11.01$ & 1.135 (t-value) & 0.259 \\
\hline Mean \pm SD blood loss, ml & $52.30 \pm 17.58$ & $50.08 \pm 15.82$ & 0.655 (t-value) & 0.514 \\
\hline Mean \pm SD postoperative hospital stay, days & $4.36 \pm 0.83$ & $4.45 \pm 0.97$ & 0.542 (t-value) & 0.589 \\
\hline
\end{tabular}

BMI, body mass index; COPD, chronic obstructive pulmonary disease; SD, standard deviation.

Table III. Vancouver Scar Scale scores for the active and the control group.

\begin{tabular}{lcrr}
\hline Outcome $^{\mathrm{a}}$ & Active group $(\mathrm{n}=50)$ & Control group $(\mathrm{n}=48)$ & t-value \\
\hline Vancouver Scar Scale score & $4.86 \pm 0.97$ & $7.54 \pm 1.30$ & 11.518 \\
Vascularity & $1.30 \pm 0.58$ & $1.92 \pm 0.71$ & 4.718 \\
Pigmentation & $1.14 \pm 0.40$ & $1.63 \pm 2.16$ & 5.336 \\
Pliability & $1.34 \pm 0.52$ & $2.27 \pm 0.84$ & 6.543 \\
Height & $1.08 \pm 0.40$ & $1.73 \pm 0.68$ & 5.771 \\
\end{tabular}

${ }^{\mathrm{a}}$ mean \pm standard deviation.
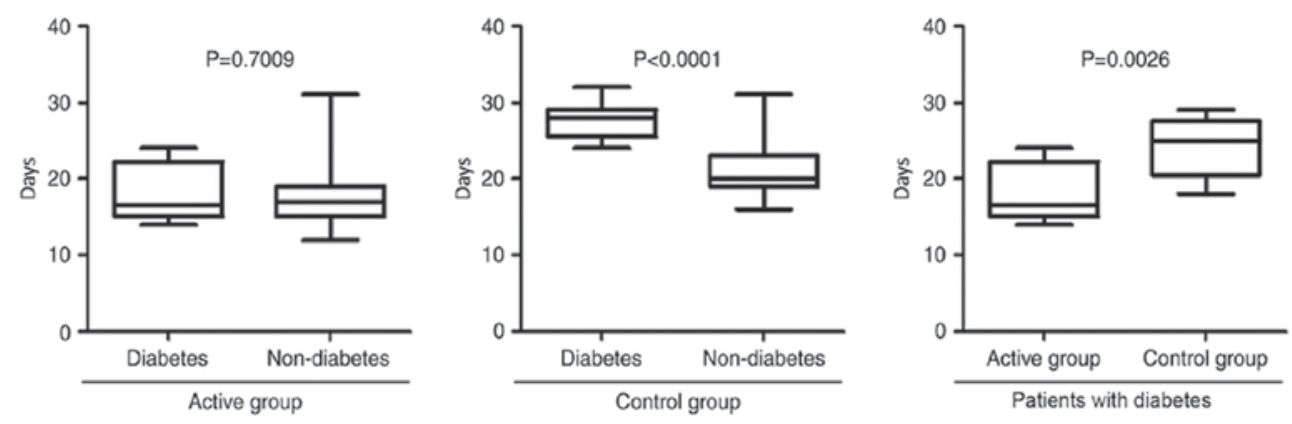

Figure 4. Mean number of days of wound healing following radical surgery for the active and the control group; the mean number of days of wound healing associated with diabetic and non-diabetic groups.

\section{Discussion}

In the present study, the scar of patients in the active group was limited to a light spot in the majority of cases. The results of the present study indicated that patients whose incisions were closed using intradermal suture with Ti-Ni memory alloy wire suture exhibited an improved cosmetic outcome compared with those for whom incisions were closed using the interrupted 
suturing technique. The cosmetic outcome was assessed using VSS. VSS is a reliable, comprehensive approach for assessing linear surgical scars (23). VSS assesses four subjective variables (vascularity, pigmentation, pliability and height) within a range of 0-13 for the total score (calculated as the sum of all four subjective variables scores), where a lower score (0-4) indicates improved healing (21).

In China, certain surgeons use discontinuous silk suture to close the skin incision $(9,24)$. Therefore, suture track scars are present on each side of the incision in numerous cases and one can observe a suture reaction, inflammation, liquefaction, infection or incision dehiscence requiring secondary suture (4). Scars are usually caused by excessive repair of skin wounds due to excessive proliferation, activation and migration of fibroblasts. Increase in the biosynthesis of fibroblasts cause excessive collagen deposition of extracellular matrix $(25,26)$. Collagen fibers also form here as a result of the body synthesizing collagen at an increased rate compared with that at which it catabolizes collagen over a longer period of time $(27,28)$.

The present study indicated that continuous intradermal suture was able to decrease scar formation compared with the control group, although patients exhibited scar hyperplasia. Despite this, intradermal suture may decrease the discomfort the hyperplastic scar causes, including prominent surface, thick texture, local pain, heat-induced itch. Intradermal suture may also improve the function of sleep quality (29-31). Typically, the time taken for wounds to heal in patients without diabetes is decreased compared with patients with diabetes (32-35). Consistent with these previous studies, it was indicated in the present study that the time taken for wounds to heal in patients with diabetes was increased compared with that of the patients without diabetes in the control group. However, the time taken for wounds to heal in patients with and without diabetes was similar in the active group. Furthermore, it was indicated that the time taken for wounds to heal in patients with diabetes differed significantly between the active and control groups, the healing time of active groups was shorter compared with that of control groups. The present study suggested that continuous intradermal suture of incision with Ti-Ni memory alloy wire may promote skin incisions to heal and decrease scar hyperplasia, and therefore this method may be recommended to other surgeons for patients undergoing mastectomy with or without axillary surgery.

The present study was a retrospective, observational cohort study and had a number of limitations. The present study was not double blind, which may have generated bias. The 2-year follow-up period was short, and the prognosis of disease was not assessed. VSS reflects the different physical characteristics carried out by the observer, reflecting different physiological aspects of wound healing and scar maturation. The present study identified that VSS scores objectively reflected scar maturation. However, the VSS does not include a self-assessment of the patient outcome.

To conclude, the intradermal suture technique offers an improved cosmetic outcome for patients undergoing mastectomy with or without axillary surgery. The present study suggested that intradermal suture using Ti-Ni memory alloy wire may represent an effective means of inhibiting scars from forming following mastectomy. For patients undergoing intradermal suture using Ti-Ni memory alloy wire, the scar was less noticeable and wound healing was improved compared with the control group, particularly in patients with diabetes.

\section{Acknowledgements}

The present study was supported by the National Science Foundation for Young Scientists of China (grant nos. 81402506 and 81602597).

\section{References}

1. Akram M and Siddiqui SA: Breast cancer management: Past, present and evolving. Indian J Cancer 49: 277-282, 2012.

2. Sehl M, Lu X, Silliman R and Ganz PA: Decline in physical functioning in first 2 years after breast cancer diagnosis predicts 10-year survival in older women. J Cancer Surviv 7: 20-31, 2013.

3. Derks MG, de Glas NA, Bastiaannet E, de Craen AJ, Portielje JE, van de Velde CJ, van Leeuwen FE and Liefers GJ: Physical functioning in older patients with breast cancer: A prospective cohort study in the TEAM trial. Oncologist 7: 946-953, 2016.

4. Joyce CW, Murphy S, Murphy S, Kelly JL and Morrison CM: Scar wars: Preferences in breast surgery. Arch Plast Surg 42: 596-600, 2015.

5. Zhang ZT, Zhang HW, Fang XD, Wang LM, Li XX, Li YF, Sun XW, Carver J, Simpkins D, Shen J and Weisberg M: Cosmetic outcome and surgical site infection rates of antibacterial absorbable (Polyglactin 910) suture compared to Chinese silk suture in breast cancer surgery: A randomized pilot research. Chin Med J (Engl) 124: 719-724, 2011.

6. Ünsal MG, Dural AC, Çelik MF, Akarsu C, Başoğlu İ, Dilege ME, Kapan $\mathrm{S}$ and $\mathrm{Al}$ ı̧ $\mathrm{H}$ : The adaptation process of a teaching and research hospital to changing trends in modern breast surgery. Ulus Cerrahi Derg 31: 34-38, 2014.

7. Peyser PM, Abel JA, Straker VF, Hall VL and Rainsbury RM: Ultraconservative skin-sparing 'keyhole' mastectomy and immediate breast and areola reconstruction. Ann R Coll Surg Engl 82: 227-235, 2000.

8. Shrotria S: The periareolar incision - gateway to the breast! Eur J Surg Oncol 27: 601-603, 2001.

9. Wang J, Zhang YF, Wang X, Wang J, Yang X, Gao YQ and Fang Y: Treatment outcomes of occult breast carcinoma and prognostic analyses. Chin Med J (Engl) 126: 3026-3029, 2013.

10. Hoeller U, Kuhlmey A, Bajrovic A, Grader K, Berger J, Tribius S, Fehlauer F and Alberti W: Cosmesis from the patient's and the doctor's view. Int J Radiat Oncol Biol Phys 57: 345, 2003.

11. O'Kane S: Wound remodeling and scarring. J Wound Care 11: 296-299, 2002.

12. Truong PT, Lee JC, Soer B, Gaul CA and Olivotto IA: Reliability and validity testing of the patient and observer scar assessment scale in evaluating linear scars after breast cancer surgery. Plast Reconstr Surg 119: 487-494, 2007.

13. Neelakantan L, Zglinski JK, Frotscher M and Eggeler G: Design and fabrication of a bending rotation fatigue test rig for in situ electrochemical analysis during fatigue testing of NiTi shape memory alloy wires. Rev Sci Instrum 84: 035102, 2013.

14. Kinoshita T, Takasugi M, Iwamoto E, Akashi-Tanaka S, Fukutomi T and Terui S: Sentinel lymph node biopsy examination for breast cancer patients with clinically negative axillary lymph nodes after neoadjuvant chemotherapy. Am J Surg 191: 225-229, 2006

15. Yamamoto T, Takahashi S, Ichihara K, Hiyama Y, Uehara T, Hashimoto J, Hirobe M and Masumori N: How do we understand the disagreement in the frequency of surgical site infection between the CDC and Clavien-Dindo classifications? J Infect Chemother 21: 130-133, 2015.

16. Li YJ, Huang XE and Zhou XD: Local breast cancer recurrence after mastectomy and breast-conserving surgery for Paget's disease: A meta-analysis. Breast Care (Basel) 9: 431-434, 2014.

17. Ouldamer L, Bonastre J, Brunet-Houdard S, Body G, Giraudeau B and Caille A: Dead space closure with quilting suture versus conventional closure with drainage for the prevention of seroma after mastectomy for breast cancer (QUISERMAS): Protocol for a multicenter randomized controlled trial. BMJ Open 6: e009903, 2016. 
18. MacFater H, MacFater W, Hill A and Lill M: Individualised follow-up booklets improve recall and satisfaction for cancer patients. N Z Med J 130: 39-45, 2017.

19. Allinson VM and Dent J: Supportive care after breast cancer surgery. Nurs Times 110: 20-23, 2014

20. Pauline T, Truong F, Yong CM, Hayashi A, Runkel JA, Phillips T and Olivotto IA: Standardized assessment of breast cancer surgical scars integrating the vancouver scar scale, short-form mcgill pain questionnaire and patients' perspectives. Plast Reconstr Surg 116: 1291-1299, 2005.

21. Nedelec B, Shankowsky HA and Tredget EE: Rating the resolving hypertrophic scar: Comparison of the vancouver scar scale and scar volume. J Burn Care Rehabil 21: 205-212, 2000.

22. Ursaru M, Jari I, Popescu R, Negru D, Naum A and Scripcariu V: Multifactorial analysis of local and lymph node recurrences after conservative or radical surgery for stage 0 -II breast cancer. Rev Med Chir Soc Med Nat Iasi 118: 1062-1067, 2014.

23. Kaartinen IS, Välisuo PO, Bochko V, Alander JT and Kuokkanen HO: How to assess scar hypertrophy - a comparison of subjective scales and Spectrocutometry: A new objective method. Wound Repair Regen 19: 316-323, 2011.

24. Zhao WX, Wang B, Yan SY and Zhang LY: Strategy of points, lines and layers in needle assisted laparoscope functional modified neck dissection through bilateral breast approach. Zhonghua Wai Ke Za Zhi 54: 823-827, 2016 (In Chinese).

25. Liebl $\mathrm{H}$ and Kloth LC: Skin cell proliferation stimulated by microneedles. J Am Coll Clin Wound Spec 4: 2-6, 2012.

26. Guo J, Lin Q, Shao Y, Rong L and Zhang D: miR-29b promotes skin wound healing and reduces excessive scar formation by inhibition of the TGF- $\beta 1 /$ Smad/CTGF signaling pathway. Can J Physiol Pharmacol 95: 437-442, 2017.

27. Li J, Chen L, Cao C, Yan H, Zhou B, Gao Y, Li Q and Li J: The long non-coding RNA LncRNA8975-1 is upregulated in hypertrophic scar fibroblasts and controls collagen expression. Cell Physiol Biochem 40: 326-334, 2016.
28. Li H, Yang L, Zhang Y and Gao Z: Kaempferol inhibits fibroblast collagen synthesis, proliferation and activation in hypertrophic scar via targeting TGF- $\beta$ receptor type I. Biomed Pharmacother 83: 967-974, 2016.

29. Kotaluoto S, Pauniaho SL, Helminen M, Kuokkanen H and Rantanen T: Wound healing after open appendectomies in adult patients: A prospective, randomised trial comparing two methods of wound closure. World J Surg 36: 2305-2310, 2012.

30. Koskela A, Kotaluoto S, Kaartinen I, Pauniaho SL, Rantanen T and Kuokkanen H: Continuous absorbable intradermal sutures yield better cosmetic results than nonabsorbable interrupted sutures in open appendectomy wounds: A prospective, randomized trial. World J Surg 38: 1044-1050, 2014.

31. Paolini S, Morace R, Lanzino G, Missori P, Nano G, Cantore G and Esposito V: Absorbable intradermal closure of elective craniotomy wounds. Neurosurgery 62 (Suppl 2): ONS490-ONS492, 2008.

32. Sorg H, Tilkorn DJ, Hager S, Hauser J and Mirastschijski U: Skin wound healing: An update on the current knowledge and concepts. Eur Surg Res 58: 81-94, 2017.

33. Nouvong A, Ambrus AM, Zhang ER, Hultman L and Coller HA: Reactive oxygen species and bacterial biofilms in diabetic wound healing. Physiol Genomics 48: 889-896, 2016.

34. Reed GW, Salehi N, Giglou PR, Kafa R, Malik U, Maier M and Shishehbor MH: Time to wound healing and major adverse limb events in patients with critical limb ischemia treated with endovascular revascularization. Ann Vasc Surg 36: 190-198, 2016.

35. Khamaisi M, Katagiri S, Keenan H, Park K, Maeda Y, Li Q, Qi W, Thomou T, Eschuk D, Tellechea A, et al: PKCס inhibition normalizes the wound-healing capacity of diabetic human fibroblasts. J Clin Invest 126: 837-853, 2016. 